\title{
Assessment of Work Related Musculoskeletal Problems among Workers Engaged in Ironing Clothes
}

\author{
Sujata Kumari*, Ritu Gupta and Jatinderjit Kaur Gill \\ Department of Family Resource Management, College of Community Science, Punjab \\ Agricultural University, Ludhiana-141004, Punjab, India \\ *Corresponding author
}

\section{Keywords}

Ironing work, Work related musculoskeletal disorder, Manual work

\section{Article Info}

Accepted: 05 April 2020 Available Online: 10 May 2020

\section{A B S T R A C T}

This investigation was conducted with an aim to study the work environment of the workers engaged in ironing clothes and to assess the postural discomfort while performing the activity. For the data collection 20 respondents were selected purposively in the age group of 30-50 years who were actively involved in ironing work. A pre-tested interview schedule was used to study the personal profile, job profile and their work environment. The results revealed that maximum number of respondents $(65.00 \%)$ worked $10-12$ hours per day. Long working hours may lead to musculoskeletal problems among workers. Regarding Posture discomfort and grip strength were assessed by posture discomfort scale, grip strength device and RULA work sheet, the analysis revealed that pain symptoms among the respondents were mainly observed in the elbow (2.95), shoulder joint (2.82), palm (2.65), followed by neck (2.52) and upper back (2.35). Grip fatigue for right and left hand was more i.e. $12.50 \%$ and $5.55 \%$ respectively. Posture analysis of wrist, neck and trunk reveals improper posture, awkward movements and prolonged standing lead to the increase in risk among workers. Investigation is required and change should be implement soon to avoid risk of musculoskeletal disorders. Therefore, proper preventive and corrective measures need to be suggested in order to improve the current scenario among the ironing workers.

\section{Introduction}

The most common factor that affects the working group is work-related musculoskeletal disorders (WMSDs).WMSDs are defined as the disorders of muscles, joints, bones, ligaments and related tissue, which are caused or aggravated primarily by work and also by the effect of immediate environment in which work is carried out.The main risk factors that contribute to musculoskeletal disorders are awkward postures attained for long duration, repetitive movements and force applied (Storheim, 2000).

In ironing work, the worker often stands at a same place for hours. His upper limbs are in repetitive motion whereas lower limbs are in static motion. Static work is defined as a work in which muscles are contracting without 
motion. The main concern with static work is that the muscles are contracted and blood flow to the muscle groups is decreased. As a result, muscle soreness and fatigue occur. The most severe effects of this risk factor could be tendonitis, tenosynovitis and epicondylitis. These factors are found to be common among occupational ironing workers (Zarra and Lambrianidis, 2014). Ironing work performed on road sides either by men or women is fully manually operated and generally lack in ergonomic aspects.

The main action done by the ironing workers of dominant hand is more of repeated shoulder flexion (65-75 degrees), elbow slight flexion and extension (30-45 degrees), wrist goes flexion(20-25 degrees), simultaneously repeated ulnar and radial, In hand $\mathrm{MCP}$ (Metacarpophalangeal) joints are extended, digital phalanges are completely flexed (Sankarganesh et al., 2017). The developing physiological and psychological disorders can lead to unsatisfied work which in turn leads to poor quality of ironing. There is a need to assess the common musculoskeletal disorders and environmental parameters of ironing workers. So, the present investigation was undertaken with the following specific objectives includes to study the job profile and work environment of workers engaged in ironing clothes and to assess the musculoskeletal problems of the selected ironing workers

\section{Materials and Methods}

The study was conducted in Ludhiana city as per convenience of the researcher. Samples of 20 workers performing ironing of clothes were purposively selected in the age group of 30-50 years. Those workers were selected who were ironing clothes on roadsides, as they work in adverse weather conditions and lack ergonomically designed table and equipment to work with. For collecting the relevant data, a pre-tested interview schedule was used to study the job profile of ironing workers and their work environment. To assess the musculoskeletal disorders experienced by the respondents, two scales were used.

\section{RULA (Rapid Upper Limb Assessment)}

This tool is used to evaluate various parameters like the posture adopted, force required, muscles action, movement of arm, wrist, neck, trunk and legs by scoring method to evaluate the level of exposure to risk factors. It is quick postural targeted method where work- related upper limb disorders have been reported such as neck pain, wrist pain, etc. Each posture was scored by observing the task by photographs and allocating scores for the body parts by using RULA worksheet. In RULA method, body parts were divided into two segments $A$ and B. Segment A includes the position of upper and lower arm and wrist whereas segment B includes the position of neck, trunk, and legs. After ranking each posture in both segments $\mathrm{A}$ and $\mathrm{B}$, a single score is to be sort out from table A and B respectively. The last step was to take final score from table $\mathrm{C}$ which finally indicates the action category ranging from 1 to 7 .

Musculoskeletal disorders experienced by respondents (Corlett and Bishop Scale 1976)

\section{Intensity of perceived musculoskeletal pain}

Intensity of pain felt by respondents were recorded by administrating body map with questionnaire to know the intensity of pain in different body parts while performing activities at workplace. The mean scores for the intensity of pain in different body parts were calculated on a five point scale ranging from 1to 5 viz. 1 for very mild and 5 for very severe pain in the affected body parts. 


\section{Grip strength of the respondents}

Grip dynamometer was used to measure the strength of the grip muscles. Grip strength was measured before starting the activity and after completion of ironing task and the grip fatigue of the respondents was calculated.

\section{Analysis of data}

Frequency, percentage, mean and standard deviation were used to analyse the personal profile, job profile, work environment, grip strength and assess the postural discomfort among respondents by using the following formula:

Mean score $=\frac{\sum \mathrm{Sn}}{\mathrm{N}}$

$S=$ Score assigned to respondents, $\mathrm{n}=$ Frequency distribution, $\mathrm{N}=$ Total number of respondents. Further, the ranks were given on the basis of mean score.

\section{Results and Discussion}

The data collected on various aspects from the respondents have been analyzed and presented from tables 1 to 6 :

\section{Personal profile of respondents}

The personal profile of respondents included age, education and monthly income. These have been discussed as under:

\section{Age}

Data enfolded in Table 1 reveals that the maximum number of respondents were in the age group of $40-50$ years $(60.00 \%)$ and 40.00 percent respondents were in the age group of the $30-40$ years.

Average age of the respondents was found as 41 years with standard deviation of \pm 5.42 .

\section{Education}

Regarding education, it was found that maximum number of the respondents $(70.00 \%)$ were uneducated and 30.00 per cent of respondents were under metric i.e. they did not even complete their schooling.

\section{Monthly income}

The table reveals that the average monthly income of the respondents was found to be Rs $3800 /-$ which is quite less. Only 35.00 per cent of respondents had monthly income between 4000-5000/-per month.

\section{Job profile of respondents}

It included information related to the job of the respondents like distance from home to work place, mode of travel, years of experience in work, working hours, weight of the iron, clothes ironed per day. The results are as under:

\section{Distance from home to work place}

Table 2 shows that maximum percentages of the respondents $(50.00 \%)$ were travelling 3-5 $\mathrm{km}$ daily from home to workplace. Whereas, 45.00 per cent respondents were covering 1-3 $\mathrm{km}$ daily to reach to the workplace and 5.00 per cent respondents were travelling 5-7 km daily, which is quite a long distance.

\section{Mode of travel}

The table further reveals that maximum number of respondents $(80.00 \%)$ reached to the workplace by bicycle, whereas 20.00 percent of respondents used bike to reach to their respective workplace.

\section{Years of experience in work}

Regarding work experience it was found that 75.00 percent respondents had work 
experience of 10-15 years and 25.00 percent respondents had experience of 15-20 years. This is quite a long one.

\section{Working hours}

It was found from table 2 that 35.00 per cent of respondents were working between 6-8 hours/day and 65.00 per cent of respondents were working between 8- 10 hours/day. Almost $99.99 \%$ of workers work in standing posture during ironing. There is no foot rest provided in the table. It affects the health of the workers, can increase pain in the lower back and feet.

\section{Weight of the iron}

The worker is often lifting the iron box while ironing in order to provide uniform ironing in all the areas of the cloth. Table 2 portrays that the average weight of the iron box was found as $7.5 \mathrm{~kg}$ with standard deviation of \pm 0.74 .

\section{Clothes ironed (per day)}

Regarding ironing clothes, it is clear from table 2 that 45.00 per cent of the respondents ironed between 100-120 clothes per day followed by 35.00 per cent of the respondents who ironed 80-100 clothes per day. Whereas, 20.00 per cent of the respondents ironed 6080 clothes per day. The average no. of clothes ironed in a day were 97.

\section{Environmental parameters of workplace}

Since the workers iron clothes on roadside, so it is very important to see further they work in congenial environmental condition or not. The study was conducted in summer months. The results are shown in table-3.

\section{Lighting}

Table 3 revealed that lighting conditions at the workplace were much above the recommended standards as the average daylight levels of the workplaces was 2005 lux. Since the activity is performed outdoors, so there was adequate sunlight to perform the activity. The recommended lighting levels for any activity to be performed is a minimum of 200-500 lux as given by Central Building Research Institute (1999) which shows that the lighting conditions at workplace were much above the recommended standards.

\section{Humidity}

Table 3 further reveals that average humidity level of the work place was63.76 per cent. The recommended humidity level was in the range of 30-60 per cent during the summer season as recommended by Grandjean (1987). All respondents stated that they were working under uncomfortable humidity level.

\section{Noise levels}

Table 3 further highlights that mean noise level of the workplaces was $52.92 \mathrm{~dB}$. Data indicates that respondents were working under recommended range of noise level which is $60 \mathrm{~dB}$.

\section{Temperature}

According to the world health organization the comfortable temperature range for human is $18^{\circ} \mathrm{C}$. Result in table 3 further depict that the temperature at the workplace were much above the recommended range i.e. $35^{\circ} \mathrm{c}$. So it can be said that the environmental parameters play a big role in the working efficiency of the workers. If in a workplace the environmental parameters go below or beyond the optimum level then it may be cause discomfort for the workers (Aggarwal and Sharma 2001).

Musculoskeletal problems experienced by the respondents

Musculoskeletal problems experienced of the 
respondents were assessed by the RULA survey tool and intensity of pain scale by Corlett \&Bishop. The results are as given in Fig-1.

Table 4 reveals the result of analysis of working posture using RULA tool(Table 6). The RULA score which was 7 indicated that investigation is required and change should be implemented soon to avoid risk of musculoskeletal disorders. As the figurelindicates the body of the worker is twisted while ironing which is a poor posture, so it may lead to pain in waist, elbow, shoulder and back. Since it is a repetitive activity and performed for long hours, so there should be a change in working posture to avoid MSDs. It was observed that by Mazumdar et al., (2000) that when a person moves his body to side bending posture, it is likely to result in work related posture deformities with epidemiological pain in upper extremities of the body. There are variant changes in ergonomics posture and they are unaware of further complications. So we need to insist and provide them with ergonomic solutions which will be helpful in preventing their musculoskeletal disorders.

\section{Musculoskeletal problems experienced by respondents (Corlett and Bishop Scale 1976)}

Table 5 reveals the mean score of the postural discomfort in affected body parts as given by the respondents. Mean ranks were assigned to the mean score calculated. It was observed that respondents felt moderate pain in elbow, shoulder joint followed by palm (right), neck, pper back, wrist, thighs and therefore, gave I, II, III, IV, V, VI ranks respectively. Whereas, respondents felt mild pain in lower back, ankles, legs and thighs as these parts got VII, VIII, IX, $\mathrm{X}$ ranks respectively. The twisting is also one among the postural problem, where twisting of wrist takes place while folding the clothes and lower back also exposed to twisting while ironing the cloth towards the left and right of worker. Therefore, it can be concluded that they are facing moderate pain in affected body parts due to unnatural postures adopted during ironing clothes. Moreover, the force applied in ironing as well as handling of load of the iron also adds to the problems of the workers. The worker often lifts the iron box while ironing in order to provide uniform ironing in all the areas of the clothes. The iron box weighs from $7 \mathrm{Kg}$ 's to 8 $\mathrm{Kg}$. These musculoskeletal problems lead to poor quality of life among the workers.

\section{Multiple responses}

Figure indicates rank on the basis of 5 point scale from very heavy exertion to very light exertion

\section{Grip strength of the respondents}

Table 6 shows that average grip strength of the respondents was $16 \mathrm{~kg}$ in right hand and $18 \mathrm{~kg}$ in left hand before doing the activity while after activity $14 \mathrm{~kg}$ in right hand and $17 \mathrm{~kg}$ in left hand. It was concluded that grip strength of respondents reduced $12.50 \%$ in right hand and $5.55 \%$ in left hand after activity. During ironing activities the muscles, tendons and joints are being used thousands of times a day, week after week, year after year. This risk of injury is greater when such jobs involve awkward posture (e.g. bent or flexed wrists, shoulder joints, palm) or forceful exertions such as repetitive overreaching. 
Table.1 Personal profile of respondents $n=20$

\begin{tabular}{|c|c|c|}
\hline Personal profile & Frequency & Percentage $(\%)$ \\
\hline \multicolumn{3}{|l|}{ Age (years) } \\
\hline $30-40$ & 8 & 40.00 \\
\hline $40-50$ & 12 & 60.00 \\
\hline Mean \pm SD & \multicolumn{2}{|c|}{$41 \pm 5.42$} \\
\hline \multicolumn{3}{|l|}{ Education } \\
\hline Uneducated & 14 & 70.00 \\
\hline Under metric & 6 & 30.00 \\
\hline \multicolumn{3}{|l|}{ Monthly Income (Rs) } \\
\hline 2000-3000 & 5 & 25.00 \\
\hline $3000-4000$ & 8 & 40.00 \\
\hline 4000-5000 & 7 & 35.00 \\
\hline Mean \pm SD & \multicolumn{2}{|c|}{$3800 \pm 871.77$} \\
\hline
\end{tabular}

Table.2 Job profile of respondents $n=20$

\begin{tabular}{|c|c|c|}
\hline Job profile & \multirow[t]{2}{*}{ Frequency } & \multirow[t]{2}{*}{ Percentage $(\%)$} \\
\hline $\begin{array}{l}\text { Distance from home to } \\
\text { working place }(\mathrm{km})\end{array}$ & & \\
\hline $1-3$ & 9 & 45.00 \\
\hline $3-5$ & 10 & 50.00 \\
\hline $5-7$ & 1 & 5.00 \\
\hline \multicolumn{3}{|l|}{ Mode of travel } \\
\hline Bicycle & 16 & 80.00 \\
\hline Bike & 4 & 20.00 \\
\hline \multicolumn{3}{|l|}{ Years of experience in work } \\
\hline $10-15$ & 15 & 75.00 \\
\hline $15-20$ & 5 & 25.00 \\
\hline \multicolumn{3}{|l|}{ Working hours } \\
\hline 6- 8 & 7 & 35.00 \\
\hline $8-10$ & 13 & 65.00 \\
\hline \multicolumn{3}{|l|}{ Weight of the iron (kg) } \\
\hline $7-8$ & 18 & 90.00 \\
\hline 8-9 & 2 & 10.00 \\
\hline Mean \pm SD & \multicolumn{2}{|c|}{$7.5 \pm 0.74$} \\
\hline \multicolumn{3}{|l|}{ Clothes ironed (per day) } \\
\hline $60-80$ & 4 & 20.00 \\
\hline 80-100 & 7 & 35.00 \\
\hline $100-120$ & 9 & 45.00 \\
\hline Mean \pm SD & \multicolumn{2}{|c|}{$97 \pm 15.03$} \\
\hline
\end{tabular}


Table.3 Environmental parameters of workplace

\begin{tabular}{|l|c|c|}
\hline Parameters & $\begin{array}{c}\text { Existing conditions } \\
\text { Mean \& SD }\end{array}$ & Recommended range \\
\hline Lighting (lux) & $2005 \pm 421.12$ & $200-500^{*}$ \\
\hline Humidity (\%) & $63.76 \pm 7.26$ & $30-60^{* *}$ \\
\hline Noise level (db) & $52.92 \pm 2.26$ & $60^{* * *}$ \\
\hline Temperature $\left({ }^{\circ} \mathrm{C}\right)$ & $35 \pm 2.5$ & $18^{* * * *}$ \\
\hline
\end{tabular}

Source:- *http://www.brighthubengineering.com

**http://www.ccohs.com

$* * *$ http://wwwsoundear.com

$* * * * \mathrm{WHO}$

Table.4 Postural analysis using RULA tool

\begin{tabular}{|c|c|c|c|}
\hline \multicolumn{4}{|c|}{ RULA } \\
\hline $\begin{array}{c}\text { Wrist Posture } \\
\text { Score (A) }\end{array}$ & $\begin{array}{c}\text { Neck, Trunk and } \\
\text { Posture Score(B) }\end{array}$ & (Final score) & Action category \\
\hline 7 & 10 & 7 & $\begin{array}{l}\text { Investigation and } \\
\text { implement change }\end{array}$ \\
\hline
\end{tabular}

Table.5 Musculoskeletal problems experienced by respondents $n=20$

\begin{tabular}{|l|c|c|}
\hline Body parts & Mean Score & Mean rank \\
\hline Elbow & 2.95 & I \\
\hline Shoulder joint & 2.82 & II \\
\hline Palm (Right) & 2.65 & III \\
\hline Neck & 2.52 & IV \\
\hline Upper back & 2.35 & V \\
\hline Wrist & 2.25 & VI \\
\hline Lower back & 1.62 & VII \\
\hline Ankle & 1.45 & VIII \\
\hline Palm (Left) & 1.32 & IX \\
\hline Thighs & 0.65 & X \\
\hline
\end{tabular}

Table.6 Grip strength of the respondents

\begin{tabular}{|l|c|c|}
\hline Grip strength (kg) & Right hand & Left hand \\
\hline Before activity & 16 & 18 \\
\hline After activity & 14 & 17 \\
\hline $\begin{array}{l}\text { Reduction in grip } \\
\text { (\%)/grip fatigue }\end{array}$ & 12.50 & 5.55 \\
\hline
\end{tabular}


Work related Musculoskeletal Disorders (WMSDs) are major health problems among ironing workers, which may be due to performing physical work for a prolonged time period, undefined manual and repetitive work. Ironing work is the fully manual operated and generally lacking in ergonomic design. From the above data it has been proved that the musculoskeletal discomfort is the variantly seen in ironing workers. If left untreated, then it may lead to MSDs.

The data have been collected for various regions of the body such as elbow, shoulder joint, palm (right), neck etc. Result of this study recommends that the comfort of the working activity of the ironing workers can be improved by ergonomic investigation. There is a need for some ergonomic intervention to prevent musculoskeletal disorders among these workers.

\section{References}

Aggarwal M and Sharma P (2001) Ergonomic assessment of activities performed by women workers in food processing units of Nainital District. M.Sc. thesis, G.B. Pant University of Agriculture and Technology, Pantnagar, India

Anand V (2014) Study on prevalence of musculoskeletal disorders among ironing workers in occupational laundry shops. ISSN14 : 1490-91.

Corlett N E and Bishop R P (1976) A technique for assessing postural discomfort. Ergonomics 19 : 175-82.
Grandjean E (1987) Ergonomics in computerized offices. Taylor and Francis, London.

Humidity: best indoor humidity range for humanhttp://www.brighthubengineering .com

Lighting ergonomics- survey and solution: $\mathrm{OSH}$ Answer fact sheet http://www.ccohs.com

Mazumdar D, Purkaytha S S and Kumar R (2000) Maximum acceptable weight to lift in 180 degree turning asymmetric tasks. Advances in Ergonomics, Occupational Health and Safety 12 : 196-99.

Mc Atamney L and Corlett N E (1993) Based on RULA: a survey method for the investigation of work-related upper limb disorders. Appl. Ergonomics 24 : 91-99.

Sankarganesh A, Vigneshwaran S, Shrisruthi S and Kumar S V (2017) Prevalence of work-related musculoskeletal problems among ironing workers. International Journal of Advanced Research (IJAR) 5: 204-10.

Storheim K (2000) The effect of intensive group exercise in patients with chronic low back pain. Advances in Physiotherapy 2: 113-23.

The average noise level your ears can handle over a day. http://wwwsoundear.com retrieved on Nov17, 2017.

Zarra T and Lambrianidis T (2014) Musculoskeletal disorders amongst Greek endodontists: A national questionnaire survey. International endodontic J 47: 713-811.

\section{How to cite this article:}

Sujata Kumari, Ritu Gupta and Jatinderjit Kaur Gill. 2020. Assessment of Work Related Musculoskeletal Problems among Workers Engaged in Ironing Clothes. Int.J.Curr.Microbiol.App.Sci. 9(05): 186-193. doi: https://doi.org/10.20546/ijcmas.2020.905.021 